http://doi.org/10.35784/iapgos.2828

\title{
FIBRE OPTIC BRAGG STRUCTURES WITH MONOTONIC APODISATION CHARACTERISTICS
}

\section{Jacek Klimek}

Lublin University of Technology, Faculty Electrical Engineering and Computer Science, Lublin, Poland

Abstract. The article discusses the principle of operation and the structure of chirped and uniform gratings. It presents the method of producing gratings with monotonic apodisation characteristics, and compares the spectral features of produced gratings with the those obtained by mathematical modelling.

Keywords: apodised Bragg gratings, optical fibre sensors, FBG, CFBG

\section{ŚWIATLOWODOWE STRUKTURY BRAGGA O MONOTONICZNEJ CHARAKTERYSTYCE APODYZACJI}

Streszczenie. W artykule omówiono zasadę działania i budowę siatek chirpowych oraz siatek jednorodnych., przedstawiono sposób wytwarzania siatek o monotonicznej charakterystyce apodyzacji, porównano charakterystyki spektralne siatek wytworzonych z charakterystykami uzyskanymi metoda modelowania matematycznego.

Słowa kluczowe: apodyzowane siatki Bragga, czujniki światłowodowe, FBG, CFBG

\section{Introduction}

Sensors using fibre-optic Bragg gratings as measuring transducers enable non-invasive measurements in medicine and industry [6]. Due to their small dimensions and insensitivity to the external electromagnetic field, the area of application of this type of sensors is constantly increasing [2, 3, 10]. Research on their applications has been going on for several decades.

The most frequently used method of producing Bragg structures on optical fibres is the phase mask inscription method. It is a well-known method, the advantages of which are the small number of elements necessary to produce the grating and low vibration sensitivity. The disadvantage, however, is the cost of phase masks and the inscription of the structure to a specific wavelength.

The conducted works allow to determine the possibility of shaping the spectral characteristics of structures, and thus influencing the metrological properties of sensors based on them. This is important because the commercially available Bragg gratings are characterised by a limited range of available parameters. Such structures are often optimised for use in telecommunications.

Some types of Bragg gratings, such as tilted fibre Bragg gratings, are not commercially available. Due to the sensitivity to temperature and stress, Bragg gratings are used as sensors of these physical quantities [1, 16]. The most frequently used phenomenon is the shift of the Bragg resonance wavelength under the influence of temperature or stress [12, 13, 17].

There are many types of Bragg gratings, the most important of which, due to the geometric distribution of the refractive index, are: uniform fibre Bragg gratings (FBGs), tilted fiber Bragg gratings (TFBGs), chirped fiber Bragg gratings (CFBGs) and long-period gratings (LPGs).

Each type of grating can have different distribution profiles of the refractive index change along the length of the grating, i.e. apodisation. Grating apodisation changes its spectral characteristics and the potential area of its applications $[8,9,13,18]$.

Figure 1 shows examples of the spectral transmission characteristics obtained from numerical calculations in the OptiGrating Optiwave Systems Inc. environment. Figure 1a shows the spectral characteristics of a uniform grating with an apodisation profile described by the constant function $f(x)=1$, Figure $1 \mathrm{~b}$ shows the spectral characteristics of a grating with a Gauss apodisation profile.
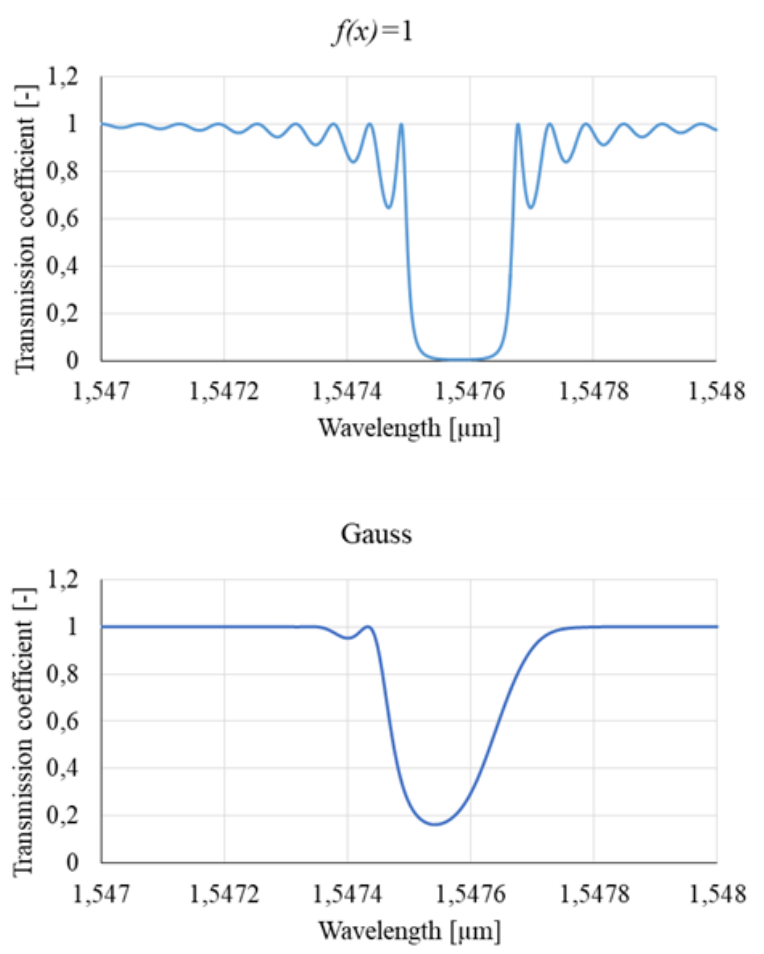

b)

Fig. 1. Spectral characteristics of gratings with different apodisation functions a) apodisation by $f(x)=1$, b) apodisation by Gaussian function

For the apodisation described by the constant function $f(x)=1$, the transmission characteristic shows sidebands which are strongly damped on the Gauss-type transmission characteristics. The most commonly used apodisation profiles in the production technology of Bragg gratings are presented in the form of equations (1-5).

Gauss profile:

$$
T=\exp \left[-a\left(\frac{z}{L}\right)^{2}\right] \quad-\frac{L}{2} \leq z \leq \frac{L}{2}
$$

Hamming profile:

cosine profile:

$$
\mathrm{T}=\frac{1+\mathrm{a} \cos \left(\frac{2 \pi \mathrm{z}}{\mathrm{L}}\right)}{1+\mathrm{a}} \quad-\frac{\mathrm{L}}{2} \leq \mathrm{z} \leq \frac{\mathrm{L}}{2}
$$

$$
T=\cos ^{a}\left(\frac{\pi z}{L}\right) \quad-\frac{L}{2} \leq z \leq \frac{L}{2}
$$


hyperbolic tangent profile:

$$
T=\left\{\begin{array}{lr}
\frac{1}{\tanh (a)} \tanh \left(\frac{2 a\left(z+\left(\frac{L}{2}\right)\right)}{L}\right) & -\frac{L}{2} \leq z<0 \\
\frac{1}{\tanh (a)} \tanh \left(\frac{2 a\left(-z+\left(\frac{L}{2}\right)\right)}{L_{g}}\right) & 0 \leq z \leq \frac{L}{2}
\end{array}\right.
$$

Cauchy profile:

$$
T=\frac{1-\left(\frac{2 z}{L}\right)^{2}}{1-\left(\frac{2 a z}{L}\right)^{2}} \quad-\frac{L}{2} \leq z \leq \frac{L}{2}
$$

Parameter $a$ is used to control the shape of the apodisation profile, $z$ is the axis along which the grating is written, $L$ is the length of the grating. Unfortunately, the main problem in the selection of apodisation is the inverse relationship between the FWHM parameter and the noise characteristics of the group delay ripple (GDR), because apodisation reduces the reflectance and reduces the effective length of the grating [18]. Smoother and more concentrated, with larger values in the middle, the apodisation profile for chirped gratings reduces the spectral reflectance and the value of the half-width of the grating [4].

\section{Modification of the distribution of the apodisation function}

The apodisation characteristic is one of the main parameters influencing the spectral properties of the optical Bragg grating. It results from the magnitude of changes in the refractive index along the length of the entire structure, affecting the effective refractive index in the optical fibre core [5]. One way to obtain a specific apodisation is to use a spatially differentiated distribution of the radiation intensity of the laser beam used to produce Bragg sieves. Changing the distribution of the apodisation function enables the elimination of unfavourable spectral properties such as, for example, sidebands [7, 19], as well as enables the shaping of the spectral characteristics of the produced grating and its modification for a specific application. The transverse distribution of the laser beam is described by the Gauss function. Modification of this type of profile in order to obtain a monotonic apodisation function is possible through the use of a slit and a selective selection of a part of the radiation intensity distribution characteristic of the rising or falling slope.

An uncomplicated method of controlling the apodisation shape of the produced periodic structures was developed. A method has been proposed in which the change of the apodisation profile can be easily achieved by placing a slot in the laser beam that records the structures. Such a slit should cover the laser beam in a strictly defined place. Figure 2 shows the method of controlling the apodisation shape of the produced periodic structures. The laser beam is $12.5 \mathrm{~mm}$ wide, while the produced Bragg structures, after using the slit, have a length of $5 \mathrm{~mm}$.

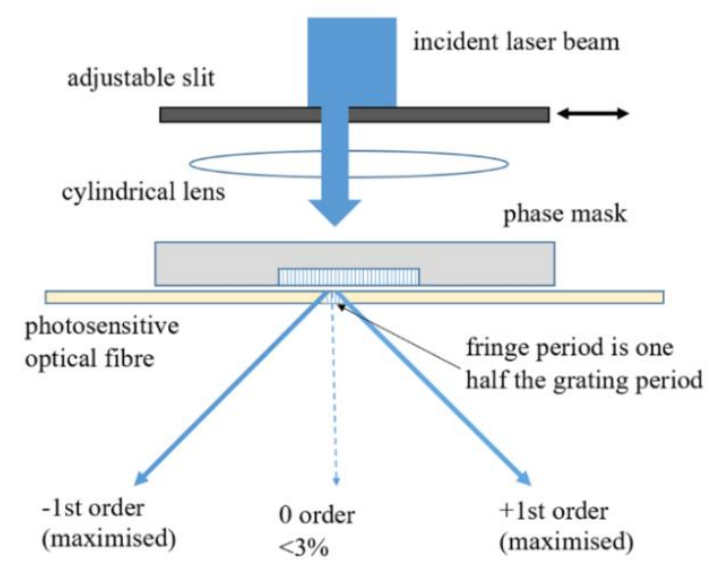

Fig. 2. Modification of the apodisation profile
The aperture that modifies the intensity distribution of the UV laser radiation has the ability to change its position along the mask as shown in Figure 2. It is located between the phase mask and the source of UV radiation. On the characteristic showing the distribution of the intensity of the UV laser radiation, this aperture is located on one of the slopes of this characteristic (Fig. 3a and Fig. 3b). As can be seen, the shape of the radiation intensity distribution of the entire laser beam is described by the Gaussian curve, while selecting the appropriate part of the beam, a monotonic profile of radiation intensity changes is obtained.

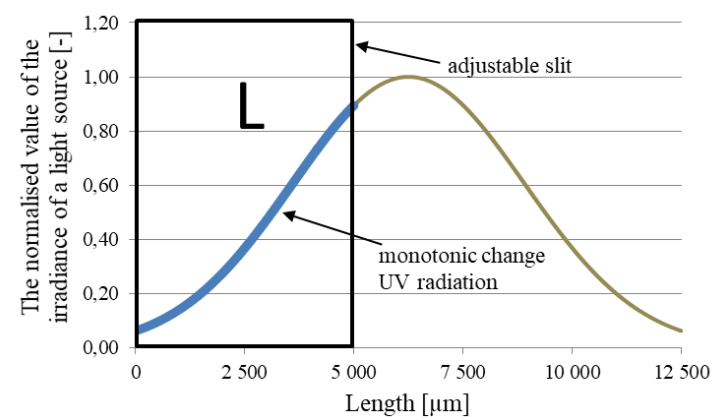

a)

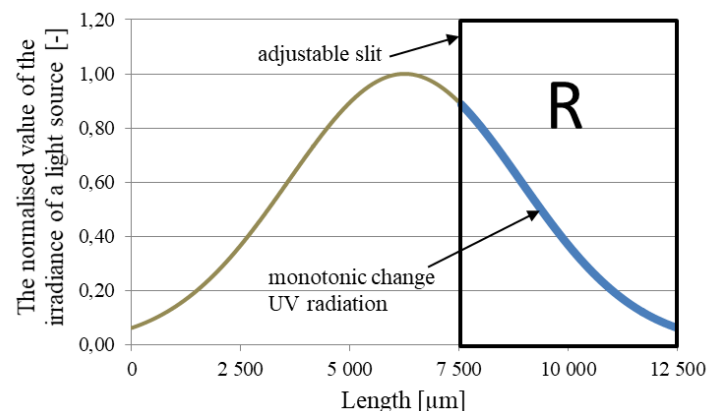

b)

Fig. 3. Change of apodisation by means of a slot of adjustable width located on a) rising profile of the laser beam marked as $L, b$ ) falling profile of the laser beam $R$

With the help of appropriate masks, uniform or chirped gratings are obtained. The principle of the chirped grating is that waves of different length are reflected in different parts of the grating depending on the period of change of the refractive index. In this way, shorter wavelengths are reflected in the part of the grating where the period is smaller and similarly longer waves are reflected in the part of the grating where the period is longer, as shown in Figure 4a. For comparison, the grating without chirp is shown in Figure 4b.

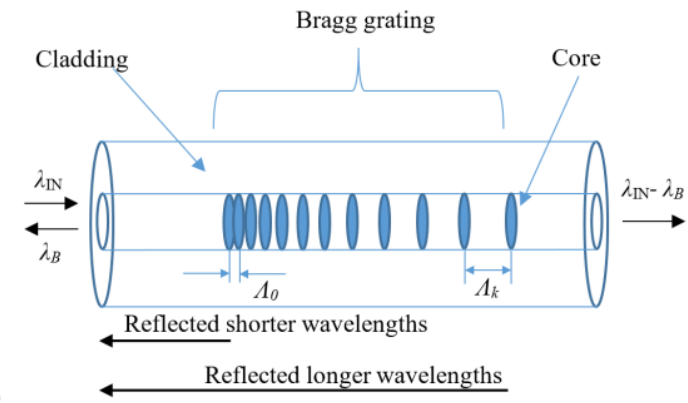

a)

Bragg grating

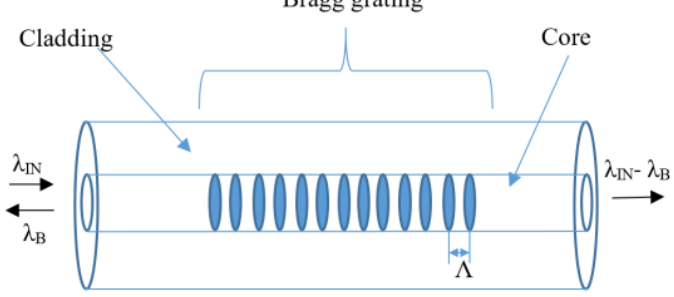

b)

Fig. 4. Scheme and principle of operation of a fibre Bragg grating: a) with chirp, b) without chirp 
In the described case, the distance travelled by shorter waves is smaller than in the case of longer waves. The opposite case can be obtained by changing the direction of the optical signal input (input on the right), then longer waves will be reflected earlier, thus they will travel a shorter distance. The measure of the phase mask chirp used to produce the chirped grating is the change in the period of the mask in relation to its length and is expressed in the unit nm/cm. For a mask with a length of $25 \mathrm{~mm}$, a $1 \mathrm{~nm} / \mathrm{cm}$ chirp and a central period of the mask, e.g. $1060 \mathrm{~nm}$, the period at the beginning of the mask is $1.25 \mathrm{~nm}$ lower than $1060 \mathrm{~nm}$, and at the end of the mask is $1.25 \mathrm{~nm}$ higher. For the produced gratings, their chirp will assume half the chirp value of the phase mask. This type of grating is produced by changing the period along the length of the optical fibre or by changing the effective refractive index depending on the length of the grating, and by both of these effects simultaneously, as shown in equation 6 .

$$
\lambda_{\mathrm{B}}(\mathrm{z})=2 \mathrm{n}_{\mathrm{eff}}(\mathrm{z}) \Lambda(\mathrm{z})
$$

The simplest chirped gratings are those whose period changes linearly according to the equation below:

$$
\Lambda(\mathrm{z})=\Lambda 0+\Delta \Lambda \mathrm{z},
$$

where $\Lambda_{0}$ is the initial period and $\Delta \Lambda$ is the linear change of the period along the fibre length $z$.

\section{Obtained results}

Research has been carried out on the influence of changes in the period of the gratings on their spectral characteristics. For this purpose, models of Bragg structures were built without chirp and corresponding to the chirp values of phase masks provided by the laboratory, i.e. $0.05 \mathrm{~nm} / \mathrm{cm}, 0.5 \mathrm{~nm} / \mathrm{cm}$ and $5 \mathrm{~nm} / \mathrm{cm}$. Then, their spectral characteristics were determined numerically (Fig. 5, Fig. 6) and compared with the actual spectral characteristics of the gratings that were produced (Fig. 7). The value of the refractive index modulation amplitude determined by the equation was adopted for the calculations:

$$
\Delta \mathrm{n}_{\mathrm{AC}}=\frac{\lambda_{\mathrm{B}} \cdot \operatorname{atanh}\left(\sqrt{\mathrm{R}_{\max }}\right)}{\pi \mathrm{L} \Gamma},
$$

where $R_{\max }$ is the maximum value of the grating reflection coefficient, $L$ is the grating length, and the parameter $\Gamma$ determines what part of the energy is propagated in the fibre core; this parameter takes a value from 0 to 1 and is described by the equation:

$$
\Gamma=\frac{\pi^{2} \mathrm{~d}^{2} \mathrm{~N}^{2}}{\lambda_{\mathrm{B}}^{2}+\pi^{2} \mathrm{~d}^{2} \mathrm{~N}^{2}},
$$

where $d$ is the diameter of the core and $N$ is a numerical aperture.

For the SMF-28 fibre, the parameter $\Gamma$ takes the value of 0.7 , which means that $30 \%$ of the energy is propagated in the cladding and $70 \%$ in the core [15].

In order to analyse the influence of changing the grating's physical parameters on its spectral characteristics, numerical calculations were performed in the OptiGrating Optiwave Systems Inc. environment. The analysis concerned parameters such as chirp and grating apodisation. OptiGrating is an environment that enables the design and analysis of sensors based on fibre Bragg gratings. Figure 5 shows the transmission characteristics of the gratings obtained by mathematical modelling with the use of the OptiGrating software. Gauss apodization profile was used for uniform gratings without chirp, with $0.05 \mathrm{~nm} / \mathrm{cm}$ chirp, $0.5 \mathrm{~nm} / \mathrm{cm}$ chirp and $5 \mathrm{~nm} / \mathrm{cm}$ chirp. Gratings chirp have been matched to the appropriate masks provided by the laboratory in order to easily compare the parameters of the simulated and produced gratings.

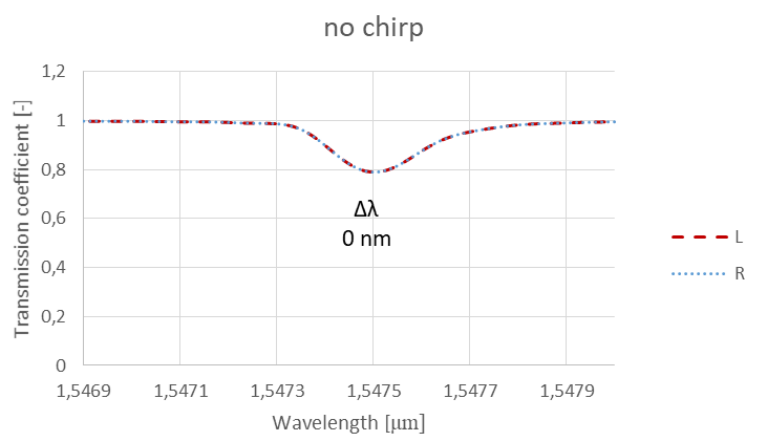

a)

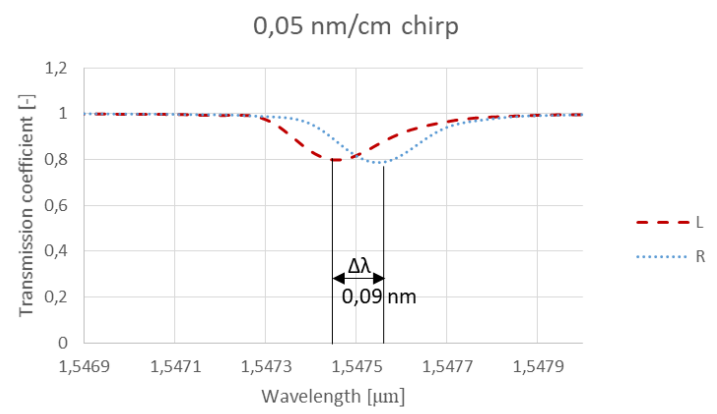

b)

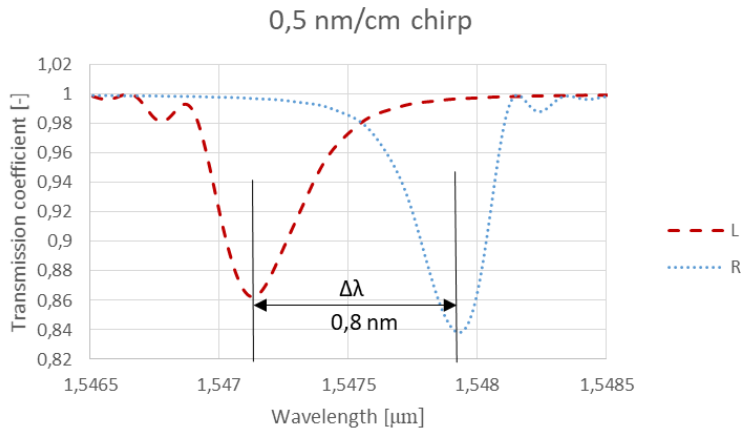

c)

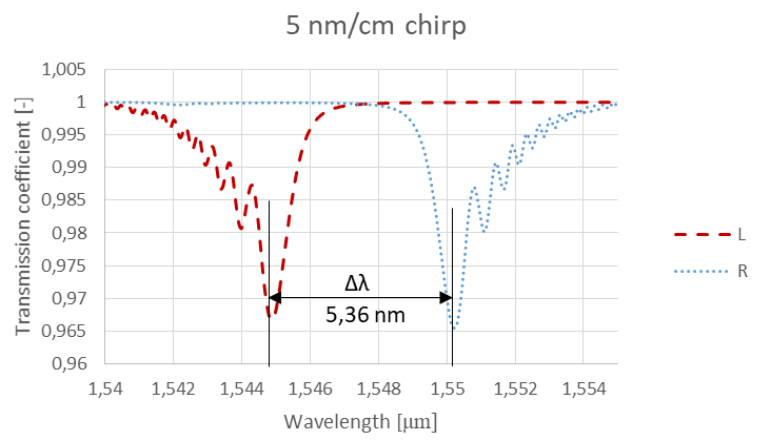

d)

Fig. 5. Spectral characteristics of grids with Gauss apodisation profile, a) without chirp, b) with a $0.05 \mathrm{~nm} / \mathrm{cm}$ chirp, c) with a $0.5 \mathrm{~nm} / \mathrm{cm}$ chirp, d) with a $5 \mathrm{~nm} / \mathrm{cm}$ chirp

Gauss apodisation shortens the effective length of the grating and affects the shape of the spectral characteristics, it is visible for gratings with a higher chirp value (Fig. 5d). For gratings recorded with chirp masks, a shift in the central Bragg resonance length for the $L$ and $\mathrm{R}$ positions is visible. The shift is the greater the greater the chirp value of the phase mask used. The smallest Bragg resonance shift value was obtained for gratings with a $0.05 \mathrm{~nm} / \mathrm{cm}$ chirp, this shift is $0.09 \mathrm{~nm}$, for gratings with a $0.5 \mathrm{~nm} / \mathrm{cm}$ chirp the shift is $0.8 \mathrm{~nm}$, while for gratings with a $5 \mathrm{~nm} / \mathrm{cm}$ chirp the shift is the largest and amounts to $5.36 \mathrm{~nm}$. 
Figure 6 shows the transmission characteristics of the gratings obtained from mathematical modelling with the use of the Optigrating software. The apodisation profile described by the function $f(x)=1$ was used for the calculations.

no chirp

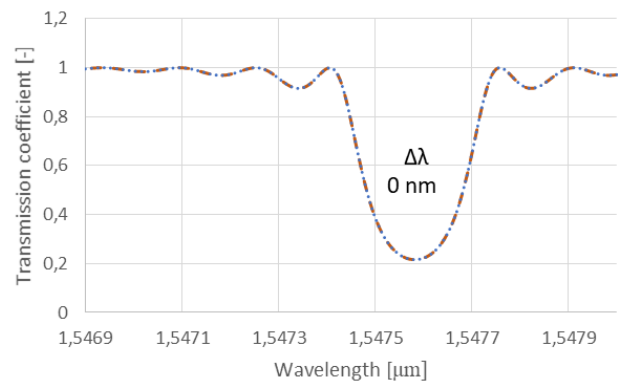

a)

$0,05 \mathrm{~nm} / \mathrm{cm}$ chirp

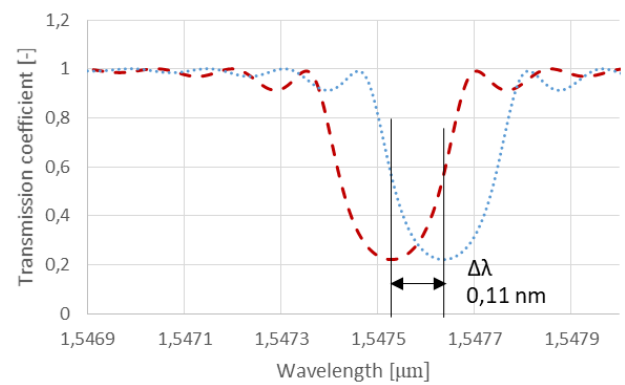

b)

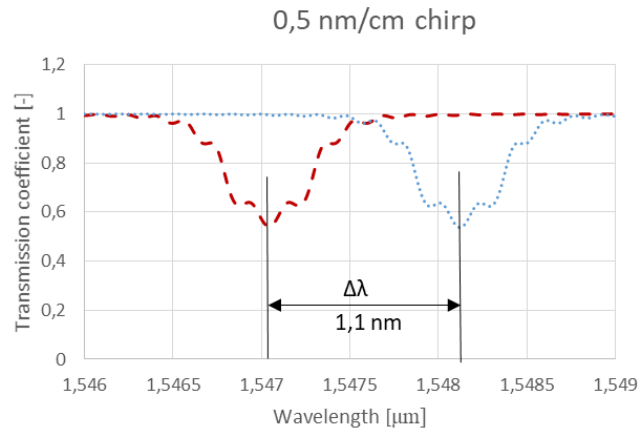

c)

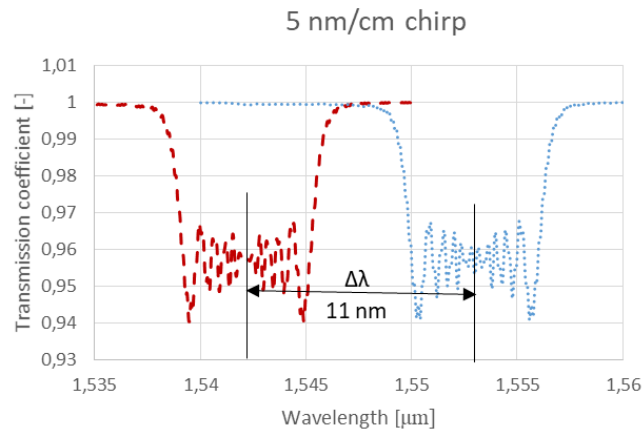

d)

Fig. 6. Spectral characteristics of grids with apodisation profile $f(x)=1$, a) without chirp, b) with a $0.05 \mathrm{~nm} / \mathrm{cm}$ chirp, c) with a $0.5 \mathrm{~nm} / \mathrm{cm}$ chirp, d) with a $5 \mathrm{~nm} / \mathrm{cm}$ chirp

The effective length of the grating recorded with apodisation with the profile $f(x)=1$ is the same as the slot, i.e. $5 \mathrm{~mm}$. There is a visible decrease in transmissivity for the Bragg resonance wavelength. The shift for the $L$ and $R$ edges for gratings with a chip is greater than for a Gaussian grating. The shift is the greater the higher the chirp value of the phase mask used, similar to the case of Gaussian gratings. The smallest Bragg resonance shift value was obtained for gratings with a $0.05 \mathrm{~nm} / \mathrm{cm}$ chirp, his shift is $0.11 \mathrm{~nm}$, for gratings with a $0.5 \mathrm{~nm} / \mathrm{cm}$ chirp the shift is $1.1 \mathrm{~nm}$, while for gratings with a $5 \mathrm{~nm} / \mathrm{cm}$ chirp the shift is the largest and amounts to $11 \mathrm{~nm}$.

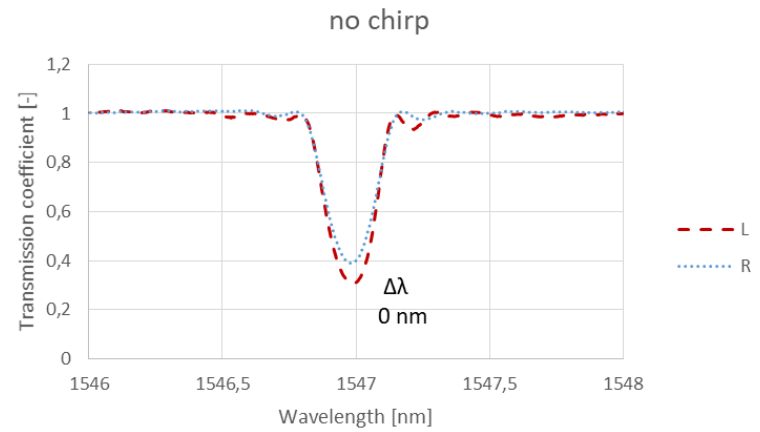

a)

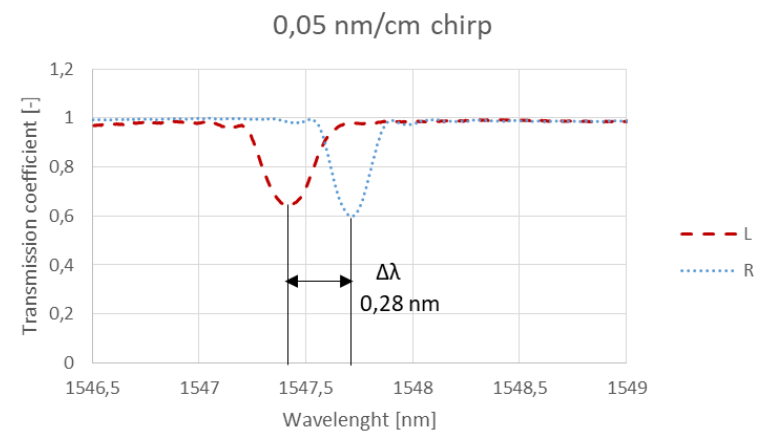

b)

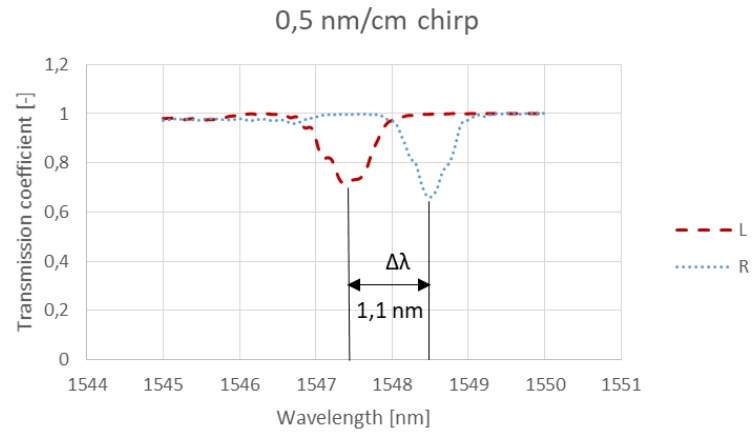

c)

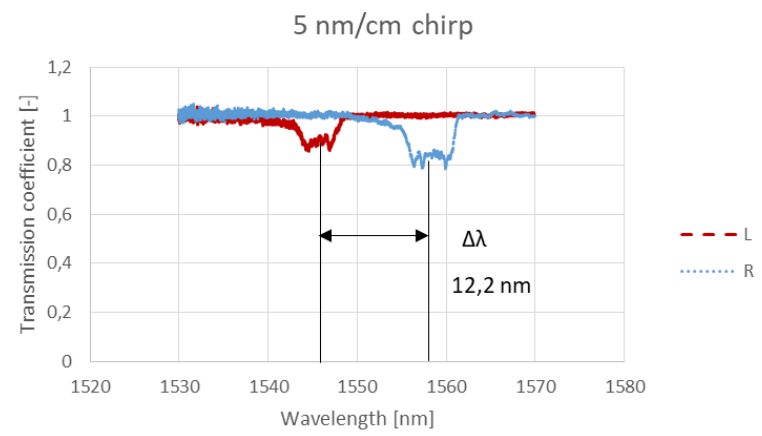

d)

Fig. 7. Spectral characteristics of gratings produced in the laboratory, a) without chirp, b) with a $0.05 \mathrm{~nm} / \mathrm{cm}$ chirp, c) with a $0.5 \mathrm{~nm} / \mathrm{cm}$ chirp, d) with a $5 \mathrm{~nm} / \mathrm{cm}$ chirp

The spectral characteristics of the produced gratings are similar to those of the gratings modelled with the $f(x)=1$ profile For the gratings with a $0.5 \mathrm{~nm} / \mathrm{cm}$ chirp, the identical shift for the $L$ and $R$ slopes was obtained, amounting to $1.1 \mathrm{~nm}$, for the gratings with a $5 \mathrm{~nm} / \mathrm{cm}$ chirp, the difference between the produced and modelled gratings was $1.2 \mathrm{~nm}$, while for the gratings with a $0.05 \mathrm{~nm} / \mathrm{cm}$ chirp, the difference was $0.17 \mathrm{~nm}$. 


\section{Summary and conclusions}

For gratings recorded with chirp masks, a shift in the central Bragg resonance length is visible for the $L$ and $R$ positions, i.e. the rising and falling slopes. The shift is the greater the higher the chirp value of the applied phase mask. The smallest Bragg resonance shift values below $1 \mathrm{~nm}$ were obtained for gratings with a chirp of $0.05 \mathrm{~nm} / \mathrm{cm}$, which is related to a small change in the period of the phase mask along its length. The greatest change in wavelength, amounting to a dozen or so nanometers, was obtained for gratings with a chirp of $5 \mathrm{~nm} / \mathrm{cm}$. When inscription uniform gratings - without chirp, no shift in the Bragg resonance wavelength for the $L$ and $R$ slopes was demonstrated. The above method of modifying the apodisation profile can be used to shape the spectral characteristics as well as to control the central Bragg resonance wavelength. The correct position of the slit relative to the phase mask as well as the slit width can change the shape of the spectrum as well as the Bragg resonance wavelength.

\section{References}

[1] Chehura E., James S. W., Tatam R. P.: Temperature and strain discrimination using a single tilted fibre Bragg grating. Optics Communications 275, 2007, 344-347.

[2] Dong B et al. Simultaneous measurement of temperature and force based on a special strain-function-chirped FBG. Sensors and Actuators A 147, 2008, 169-172.

[3] Ecke W. et al.: Optical fiber grating sensor network for monitoring refractive index and temperature distributions in fluids. Proc. SPIE 3783, 1999, 176-183.

[4] Ennser, K., Zervas, N., Laming, R. L.: Optimization of apodized linearly chirped fiber gratings for optical communications. IEEE Journal of Quantum Electronics 34(5), 1998, 770-778.

[5] Gillooly A. M. et al.: Implementation Of Chirped Fiber Bragg Gratings (CFBG) As Optical Wear Sensors. Lasers and Electro-Optics Society. The 16th Annual Meeting of the IEEE 2003.

[6] Guo T.: Fiber Grating-Assisted Surface Plasmon Resonance for Biochemical and Electrochemical Sensing. Journal of Lightwave Technology 35(16), 2017, 3323-3333.

[7] Hill K., Meltz G.: Fibre Bragg grating technology fundamentals and overview. Jr. Lightwave Techno. 15, 1997, 1263-1276.
[8] Hwang G. S. et al.: Numerical Study on Reflection Spectra of an Apodized Fiber Bragg Grating Subjected to Strain Gradients. Procedia Engineering 79, 2014, 631-639.

[9] Khalid K. S. et al.: Simulation and analysis of Gaussian apodized fiber Bragg grating strain sensor. Journal of Optical Technology 79(10), 2012, 667-673.

[10] Kinet D. et al.: Fiber Bragg Grating Sensors toward Structural Health Monitoring in Composite Materials: Challenges and Solutions. Sensors 14, 2014, 7394-7419.

[11] Kisała P.: Metrological conditions of strain measurement optoelectronic method by the use of fibre Bragg gratings. Metrology and Measurement Systems 19(3), 2012, 471-480.

[12] Kisala P., Cieszczyk S.: Method of simultaneous measurement of two direction force and temperature using FBG sensor head. Applied Optics 54(10), 2015, $2677-2687$.

[13] Lin Z. et al.: A novel method for fabricating apodized fiberber Bragg gratings. Optics and Laser Technology 35, 2003, 315-318.

[14] Markowski K. et al.: Custom FBGs inscription using modified phase mask method with precise micro- and nano-positioning. Proc. of SPIE 10031, 2016, $100311 \mathrm{H}$.

[15] Waluyo T. et al.: The effect of macro-bending on power confinement factor in single mode fiber. Journal of Physics: Conference Series 985, 2017, 012001.

[16] Weilin L. et al.: Real-Time Interrogation of a Linearly Chirped Fiber Bragg Grating Sensor for Simultaneous Measurement of Strain and Temperature. IEEE Photonics Technology Letters 23(18), 2011, 1340-1342.

[17] Zhan Y. et al.: A linearity interrogation technique with enlarged dynamic range for fiber Bragg grating sensing. Optics Communications 283, 2010, 3428-3433.

[18] Zhang H.: A novel method of optimal apodization selection for chirped fiber Bragg gratings. Optik - International Journal for Light and Electron Optics 125(5), 2014, 1646-1649.

[19] Zychowicz Ł. et al.: Methods of producing apodized fiber Bragg gratings and examples of their applications. Informatyka, Automatyka, Pomiary w Gospodarce i Ochronie Srodowiska 89(1), 2018, 60-63.

\section{Ph.D. Jacek Klimek}

e-mail: j.klimek@pollub.pl

Assistant at the Faculty of Electrical Engineering and Computer Science of the Lublin University of Technology, author of many publications on fibre optics. He obtained his Ph.D. in 2021. His research focuses on the fabrication and study of optical periodic structures called Bragg gratings. Current research interests focus on issues related to complex periodic structures.

http://orcid.org/0000-0001-8141-6136

otrzymano/received: $25.11 .2021 \quad$ przyjęto do druku/accepted: 15.12.2021

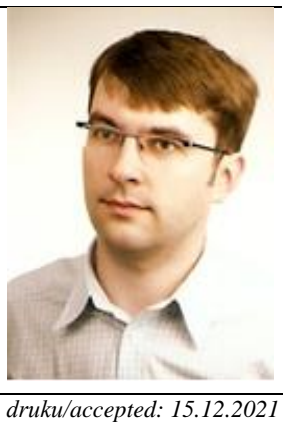

